\title{
Utilizing Quantum Dots to Enhance Solar Spectrum Conversion Efficiencies for Photovoltaics
}

Richard Savage, Hans Mayer, Matthew Lewis and Dan M. Marrujo
Cal Poly State University, College of Engineering, San Luis Obispo, CA 93407, U.S.A.

\begin{abstract}
Silicon-based photovoltaics typically convert less than $30 \%$ of the solar spectrum into usable electric power. This study explores the utilization of CdSe based quantum dots as spectral converters that absorb the under utilized UV portion of the solar spectrum and fluoresce at wavelengths near the band-gap of silicon-based solar cells. A flexible $1 \mathrm{~mm}$ thick thin-film structure that contains an array of microfluidic channels is designed and fabricated in polydimethylsiloxane (PDMS) using soft-lithographic techniques. The channels are approximately 85 microns wide by 37 microns tall and are filled with a solution containing the quantum dots. The thin-film structure can easily be attached to the surface of a single-junction solar cell. As a result, solar energy striking the coated solar cell with wavelengths less than $450 \mathrm{~nm}$, which would normally experience low conversion efficiency, are absorbed by the quantum dots which fluoresce at $620 \mathrm{~nm}$. The high energy photons are converted to photons near the band-gap which increase the overall conversion efficiency of the solar cell. The quantum dots employed in this study are fabricated with a CdSe core $(5.2 \mathrm{~nm})$ and a $\mathrm{ZnS}$ outer shell and they exhibit a $25 \mathrm{~nm}$ hydrodynamic diameter. The UV-VIS spectral transmission properties of PDMS, along with its refractive index, are determined in order to characterize the spectral conversion efficiency of the thin-film structure. A model is developed to predict the optimum path length and concentration of quantum dots required to improve the power output of an amorphous silicon solar cell by $10 \%$.
\end{abstract}

\section{PHOTOVOLTAIC TECHNOLOGY}

Photovoltaic solar cells are commonly employed to harness the enormous energy (600800 watts $/ \mathrm{m}^{2}$ ) that strikes the earth each day from the sun. The first silicon solar cell was developed at Bell Labs in 1954 and there has been a steady increase in the utilization of this sustainable energy source over the past 50 years [1]. Today, only $0.03 \%$ of the world's total power requirements are provided by the conversion of solar energy into electrical power [2]. One of the most cost effective implementations involves the utilization of crystalline silicon with conversion efficiencies typically around $15 \%$ yielding power production rates of around $\$ 0.25 / \mathrm{kWh}$, which is still high compared to $\$ 0.05 / \mathrm{kWh}$ for coal or gas fired power plants [2]. Over $90 \%$ of the photovoltaic power produced today is from single crystal silicon based panels; however, first generation silicon based solar cells do not utilize all of the radiant energy that is provided by the sun. Specifically, wavelengths below 450 nanometers are not converted effectively into usable electrical power and as much as $39 \%$ of the sun's energy is under utilized [3]. This research focuses on developing a method for improving solar cell efficiency by $10 \%$ through the process of spectral conversion, which would thereby make it competitive with thirdgeneration photovoltaics based on multi-junction thin films. The spectral conversion technique examined in this study employs an aqueous solution of quantum dots that absorbs all of the solar 
energy below $450 \mathrm{~nm}$ and then converts it to spectral energy near the band-gap of a silicon solar cell.

\section{QUANTUM DOTS}

This research explores the use of colloidal nanocrystalline CdSe quantum dots (QD) to serve as spectral converters. Spectral conversion based on organic dye molecules has been attempted but the dyes were not able to achieve very high quantum efficiencies, were unstable and exhibited limited absorption bandwidths [4]. However, solutions containing QD are very efficient (near 60\% quantum efficiency) at absorbing spectral energy from wavelengths less than $450 \mathrm{~nm}$ and can convert them through photoluminescence to visible energy at 620nm, which is near the band-gap of many c-Si solar cells [5-9]. Quantum dots are a cluster of tightly packed atoms as shown in Figure 1. Typically, they are II-VI nanocrystalline semiconductor compounds and a single quantum dot can be as small as 2 to 10 nanometers in diameter. The size of the quantum dot will determine the size of the band-gap associated with it and hence the specific wavelength for photoluminescence. The larger the quantum dot, the smaller the band-gap (longer wavelength) and the smaller the quantum dot the larger the band-gap (shorter wavelength) [10]. The CdSe/ZnS quantum dots utilized in this study were designed to fluoresce at a wavelength of $620 \mathrm{~nm}$ and the diameters of the quantum dots were approximately $5.8 \mathrm{~nm}$.

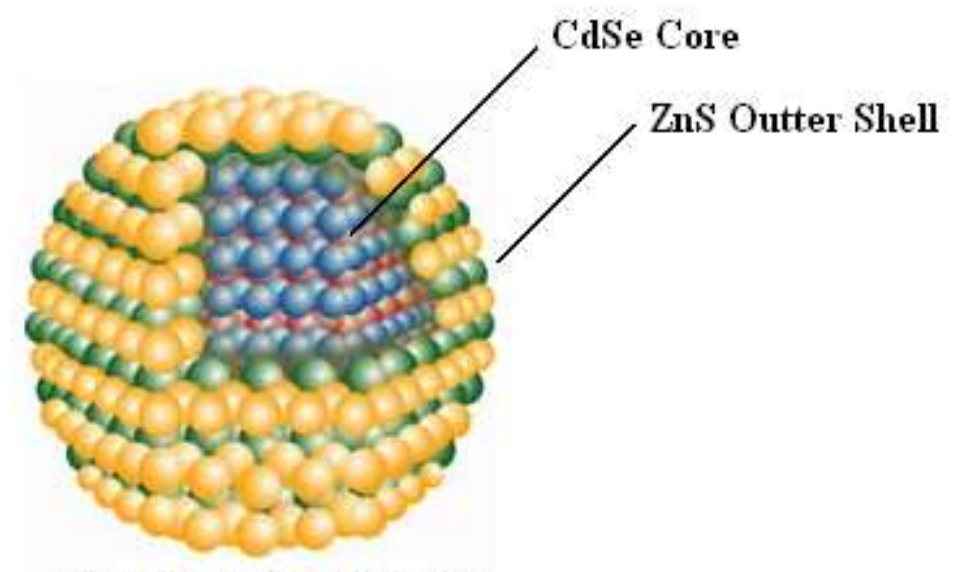

CdSe/ZnS Quantum Dot

Figure 1 - Illustration of quantum dot showing CdSe core and $\mathrm{ZnS}$ outer shell, by Evident Technology [11].

The band-gap of the CdSe core is tuned by changing its size from 2-10nm and can therefore provide a specific wavelength for fluorescence. The $\mathrm{ZnS}$ outer shell has a broad bandgap and it enhances the quantum efficiency of the core atoms and prevents oxidation of the core. In addition, the QD utilized in this study (Evident Technology) are specially coated to allow them to be soluble in aqueous solutions [12]. Figure 2 shows the wavelengths of light that are absorbed by different sizes of quantum dots along with their corresponding wavelengths of fluorescence. In order to understand the characteristics of quantum dots, it was important to measure their associated fluorescence. These measurements determine if the amount of florescence energy produced by the quantum dots could create enough additional current flow in a photovoltaic cell to significantly improve the cell's efficiency. The amount of fluorescence is dependent on 1) the number of high-energy photons that are absorbed by the quantum dots and 
2) the quantum conversion efficiency. The absorbance of the quantum dot solution is controlled by the concentration and the path-length of the quantum dot solution. The concentration of the CdSe $/ \mathrm{ZnS}$ solution (water) available from Evident Technologies was $0.25 \mathrm{mg} / \mathrm{mL}$, which will be shown to be not high enough to produce enough fluorescence to increase our solar cell's efficiency by the targeted value of $10 \%$.

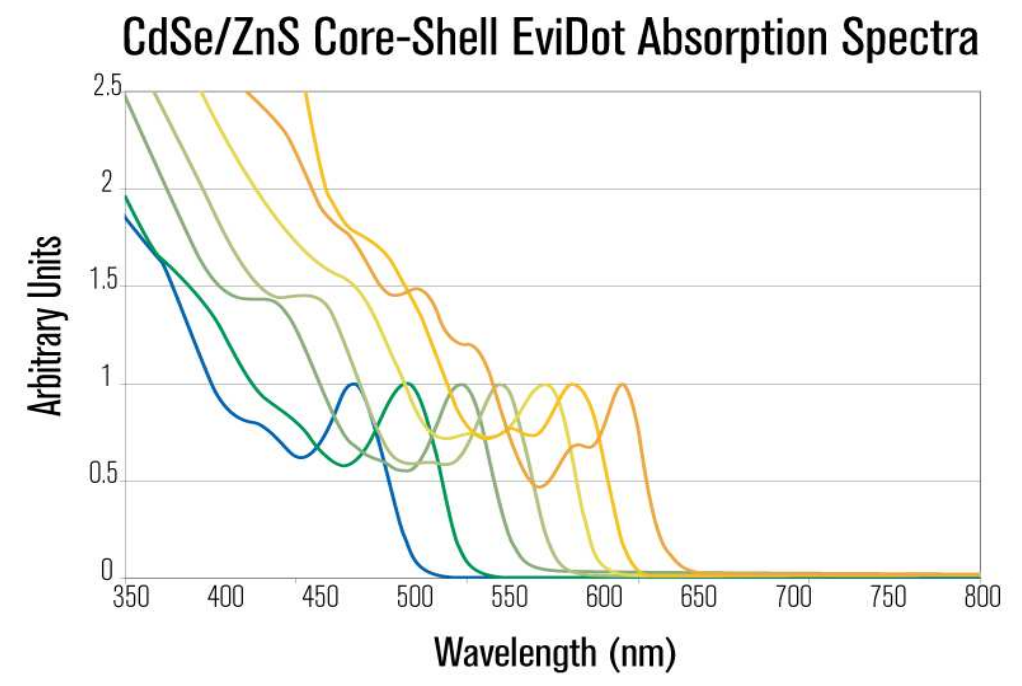

Figure 2 - Graph showing absorption profiles for Evident Technology quantum dots employed in this study [11].

\section{SOLAR CELL PERFORMANCE}

In order to increase a solar cell's spectral conversion efficiency by taking advantage of the wavelength shift provided by the quantum dots, the cell must be "coated" with a layer of material that contains the quantum dots. The coated layer must transmit all of the solar spectral wavelengths that are normally converted to electrical energy by the cell. In addition, the quantum dots in the layer must be able to absorb a significant portion of the sun's spectral energy that is not normally converted by the cell to wavelengths that are converted to electrical power. Two methods were evaluated for this "coating" process: 1) spin-coating a thin layer of quantum dots directly onto silicon and 2) forming an array of microfluidic channels that contain a high concentration of the quantum dots in solution. Coating a thin layer of QD onto silicon was explored by atomic force microscopy, but a high enough concentration of dots could not be established on the surface that yielded efficient spectral conversion. The most effective coating method involved forming microfluidic channels in a thin layer of poly(dimethylsiloxane) or PDMS (Sylgard 184, DOW), then filling the channels with a solution of quantum dots and finally adhering this microfluidic array to the surface of a solar cell.

A solar cell produces current based on the intensity of light that hits its surface. If the intensity of light decreases, the current produced by the solar cell will also decrease. In order to find the maximum power associated with a solar cell, an I-V curve must be evaluated. The maximum current $\left(\mathrm{I}_{\mathrm{mP}}\right)$ and maximum voltage $\left(\mathrm{V}_{\mathrm{mP}}\right)$ determine the maximum power $\left(\mathrm{P}_{\max }\right)$ that the cell can deliver. Utilizing a solar simulator light source, a standard c-Si solar cell was illuminated with 50,000 Lux of optical power, see Figure 3; this yielded $27.9 \mathrm{watt} / \mathrm{m}^{2}$ of 
irradiance at $620 \mathrm{~nm}$. The $\mathrm{P}_{\max }$ measured from the cell was 0.018 watts. Based on these measurements it was determined that in order to produce a $10 \%$ increase in the cell's power output $\left(\mathrm{P}_{\max }=0.02\right.$ watts $)$ the light level at $620 \mathrm{~nm}$ must be increased by $3.9 \mathrm{watt} / \mathrm{m}^{2}$. Using the equation for fluorescence and the following properties for the CdSe quantum dots (quantum efficiency $=0.60 ; \mathrm{I}_{\mathrm{o}}$ radiant power from solar simulator for wavelengths less than $450 \mathrm{~nm}=10.1$ watt $/ \mathrm{m}^{2}$; molar absorptivity $=3.4 \times 10^{5} \mathrm{~L} \mathrm{~mol}^{-1} \mathrm{~cm}^{-1}$ ) it was determined that a path length of 1000 microns and a concentration of $12.9 \mathrm{mg} / \mathrm{mL}$ would be required to achieve a fluorescence power level of $3.9 \mathrm{watt} / \mathrm{m}^{2}$.

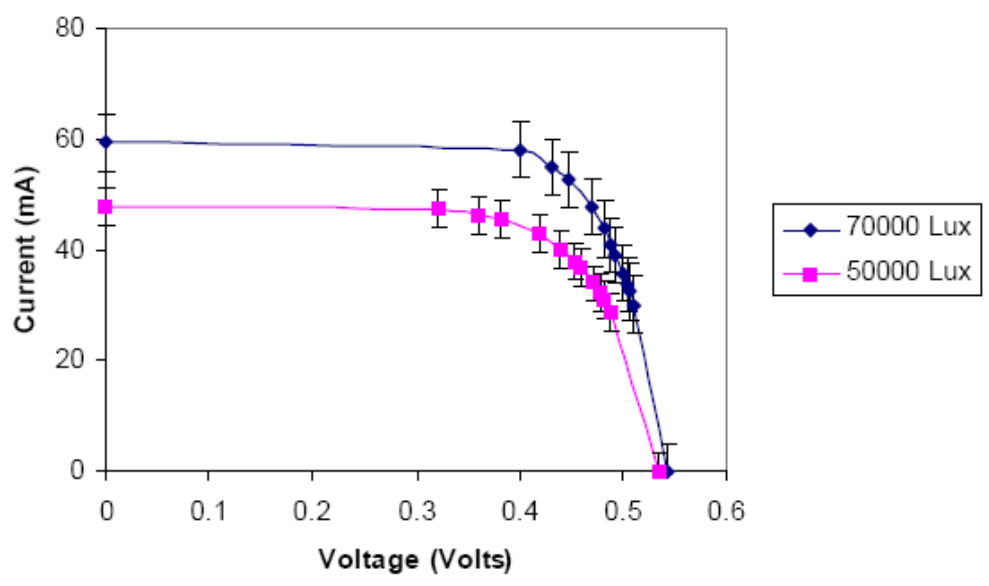

\section{Figure 3 - I-V Curve for Tested Silicon Solar Cell}

Based on these results, it was determined that a microfluidic array must be designed and fabricated with a high density of channels that would provide an absorption path length of 1000 microns and was filled with an aqueous solution of $\mathrm{CdSe} / \mathrm{ZnS}$ quantum dots.

\section{MICROFLUIDIC ARRAY}

Soft lithography was employed to fabricate an array of microfluidic channels that could hold the quantum dots in aqueous solution [13]. The polymer chosen for this process was polydimethylsiloxane (PDMS) because channels can be readily molded into it and the material is transparent in the UV-visible portion of the optical spectrum [14]. Moreover, PDMS provides a flexible substrate that can easily be adhered to the surface of a solar cell.

The fabrication process started out with a $100 \mathrm{~mm}$ diameter (100) bare silicon wafer. The wafer was stripped of its native oxide (buffered HF) and then cleaned of organic contaminants using a (9:1) mixture of sulfuric acid $\left(\mathrm{H}_{2} \mathrm{SO}_{4}\right)$ and hydrogen peroxide $\left(\mathrm{H}_{2} \mathrm{O}_{2}\right)$, also known as a piranha. Next, the wafer was rinsed in deionized water for 20 seconds and dried in a nitrogen atmosphere. The surface of the silicon wafer was dehydrated and placed into a spin coater (Laurell WS-400). Negative photoresist (SU-8 2050) was then dispensed onto the surface of the wafer and it was spun in a two-stage spin-cycle. The first cycle was for 20 seconds at $400 \mathrm{rpm}$ with an acceleration of $85 \mathrm{rpm} / \mathrm{second}$ to help spread out the SU-8. The second spin cycle was for 35 seconds at $4000 \mathrm{rpm}$ with an acceleration of $600 \mathrm{rpm} / \mathrm{second}$. This yielded a final thickness value for the resist of 37 microns. Next, the photoresist was soft baked at $95^{\circ} \mathrm{C}$ for 5 
minutes to evaporate the solvent and make the film denser. The silicon wafer was then placed into the proximity aligner (Canon PLA-501FA) and exposed with ultraviolet light through a mask containing a serpentine pattern of 85 micron wide channels. Following exposure, the film was hard baked for 6 minutes at $95^{\circ} \mathrm{C}$ and then developed in a SU-8 developer. Now all that remained on the surface of the silicon wafer was the hardened photoresist, which acted as a mold that will transfer the channel shapes into the PDMS layer. PDMS was degassed and then poured on top of the silicon wafer and placed into an oven at $80{ }^{\circ} \mathrm{C}$ for an hour, which solidified the layer. The PDMS was then peeled off of the wafer and cut into $33 \mathrm{~mm} \times 12 \mathrm{~mm}$ sections; these dimensions match the footprint of the solar cell. A final thin PDMS layer was fabricated to seal up the fluid channels. In order to bond the two substrates together, both sides were exposed to a argon plasma treatment for 2 seconds. After the two pieces of PDMS had been secured together, they were baked for one hour at $80^{\circ} \mathrm{C}$. Small holes were punched into the surface of the PDMS to access both ends of the channels. Next, a thin piece of plastic tubing was positioned into the punched holes to direct the solution into the microfluidic channels. Then an aqueous solution containing the QD was then fed into the channels and the holes were sealed shut.

\section{RESULTS \& CONCLUSIONS}

The microfluidic array was illuminated with the solar simulator and the resulting fluorescence is shown in Figure 4. Transmission of optical light through the PDMS based microfluidic array with QDs in solution was greater than $90 \%$ at $620 \mathrm{~nm}$ and reflection losses due to the attachment of the PDMS layer onto the solar cell were measured to be less than $2.8 \%$.

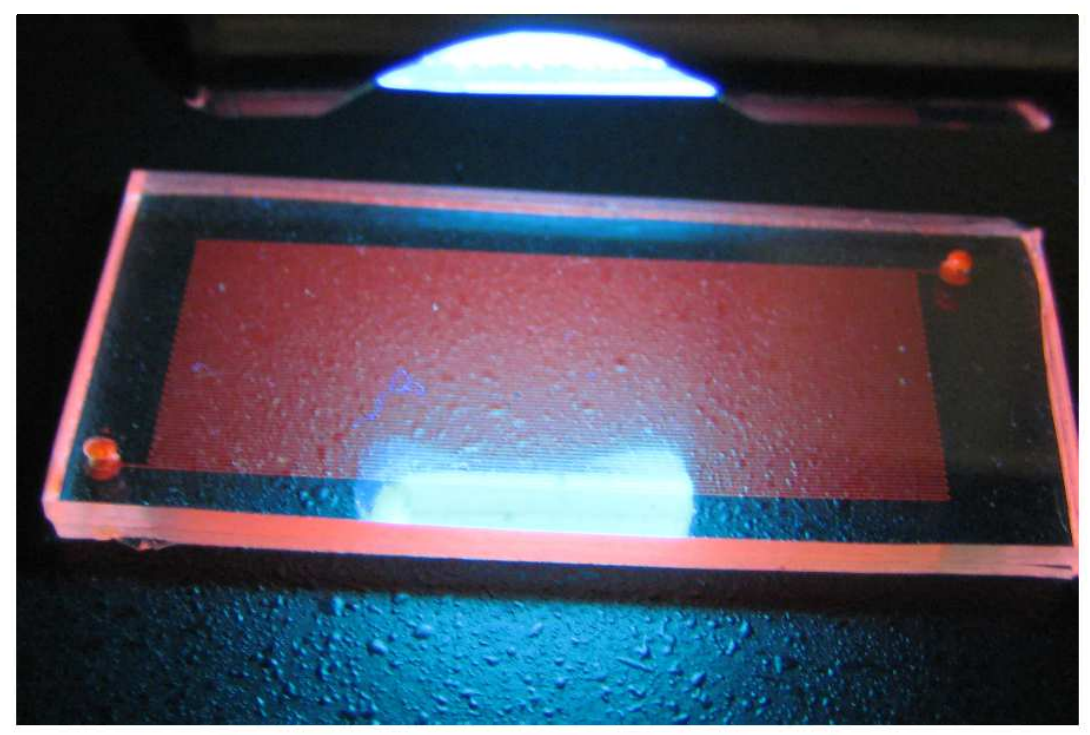

Figure 4 - Quantum Dots Suspended in Microfluidic Array \& Excited by UV Light Source

However, the heights of the microfluidic channels were only 37 microns for the test array. This severely limited the absorption path and is well short of the targeted path length of 1000 microns. A multi-step lithographic process is being developed that will enable the formation of fluid channels that are 1000 microns wide by 1000 microns high. In addition, the serpentine pattern yielded about a 50\% fill factor (area filled with QDs versus total area of 
PDMS covering the solar cell). Another significant limitation was that the highest aqueous concentration of quantum dots available from Evident Technologies was $0.25 \mathrm{mg} / \mathrm{mL}$. The combination of short path length and low concentration yielded fluorescence that increased the irradiance to the solar cell by only $4.8 \mathrm{~mW} / \mathrm{m}^{2}$. As discussed earlier, this was not enough to produce a measurable increase in the $\mathrm{P}_{\max }$ of the solar cell. An increase of at least $3.9 \mathrm{~W} / \mathrm{m}^{2}$ would be required to increase the $\mathrm{P}_{\max }$ by $10 \%$. Accordingly, the concentration of QD would need to be raised to $12.9 \mathrm{mg} / \mathrm{mL}$ and the path length increased to 1000 microns. We are currently exploring processes for synthesis QD solutions of this concentration and developing a process for fabricating microfluidic arrays with 1000 micron path lengths.

\section{ACKNOWLEDGMENTS}

The majority of this work was completed by Dan M. Marrujo as part of his MS thesis. Hans Mayer provided technical direction for the fabrication of the micro arrays. Matthew Lewis provided AFM characterization support. Funding was provided by Raytheon Corporation through donations to Cal Poly's Project Based Learning Institute and in part by the Office of Naval Research through Grants: N00014-04-1-0436 \& N00014-05-1-0855.

\section{REFERENCES}

1. D.M. Chapin, C.S. Fuller, G.L. Pearon, J. Appl. Phys, 25, 676 (1954).

2. V.S. Arunachalam, E.L. Fleischer, MRS Bulletin, 33 (4), 264-276 (2008).

3. D. Ginley, M. Green, R. Collins, MRS Bulletin, 33 (4), 355-363 (2008).

4. A. Goetzberger, W.Greubel, Appl Phys., 14, 123 (1977).

5. W. Stark, A. Meijerink, R. Schropp, J. vanRoosmalen, E. Lysen, Solar Enrgy Materials \& Solar Cells, 87, 395-409 (2005).

6. C. Strumpel, M. McCaqnn, G. Beaucarne, V. Arkhipov, A. Slaoul, V. Svrek, C. Del Canizo, I. Tobias, Solar Enrgy Materials \& Solar Cells, 91, 283-249 (2007).

7. K. Barnham, J. Marques, J. Hassard, P. O’Brien, Appl. Phys. Lett., 76, 1197-1199 (2000).

8. A. Chatten, K. Barnham, B. Buxton, et.al., Sol. Energy Mater. Sol. Cells, 75, 363-371 (2003).

9. A. Chatten, K. Barnham, B. Buxton, N. Ekins-Daukes, M. Malik, Proceedings of the Third World Congress on Photovoltaic Energy Conversion (WPEC-3), 2657-2660 (2003).

10. C. Murphy, J. Coffer, Applied Spectroscopy, 56 (1), 16A-27A (2002).

11. M. LoCascio, Evident Technology, Troy, N.Y., www.evidenttech.com.

12. D. Gerion, F. Pinaud, S. Williams, W. Parak, D. Zanchet, S. Weiss, A. Alivisatos, The Journal of Physical Chemistry B, 105 (37), 8861-8871 (2001).

13. S. Sia, G. Whitesides, Electrophoresis, 24, 3563-3576 (2003).

14. T. Fujii, Microelectronic Engineering, 61, 907-914 (2002). 